\title{
Congenital Bilateral Cataracts
}

National Cancer Institute

\section{Source}

National Cancer Institute. Congenital Bilateral Cataracts. NCI Thesaurus. Code C101194.

Cataract in both eyes that are present at birth. 